\title{
Opioid peptides and primary biliary cirrhosis
}

\author{
J R Thornton, M S Losowsky
}

\begin{abstract}
Patients with liver disease have increased plasma concentrations of the endogenous opioid peptides methionine enkephalin and leucine enkephalin. As an initial investigation to determine whether opioid peptides contribute to any of the clinical manifestations of hepatic disease nalmefene, a specific opioid antagonist devoid of agonist activity, was given to 11 patients with cirrhosis. They all experienced a severe opioid withdrawal reaction on starting the drug. In the nine patients with primary biliary cirrhosis pruritus was greatly alleviated, fatigue seemed to improve, and plasma bilirubin concentration, which had been rising, showed a modest fall in all except one patient.
\end{abstract}

These results indicate that blocking opioid receptors has an effect on some of the metabolic abnormalities of liver disease.

\section{Introduction}

Opioid peptides are the naturally occurring counterparts of opiate drugs. More than 10 of these peptides have been identified.' They have multiple actions, which are exerted via at least three classes of receptors: $\mu, \delta$, and $x .{ }^{1}$ Knowledge of the metabolism of these peptides, particularly at sites outside the central nervous system, is rudimentary. The plasma concentrations of the pentapeptides methionine enkephalin and leucine enkephalin are raised appreciably in patients with liver disease, and the increase is proportional to the severity of the disease..$^{2.5}$ In contrast the plasma concentration of the much larger opioid peptide, $\beta$ endorphin, is not increased in cirrhosis. ${ }^{6}$

As an initial investigation to determine whether increased activity of opioid peptides contributes to some of the clinical manifestations of liver disease we gave nalmefene (IVAX Laboratories, Miami, Florida), a specific opioid antagonist with no agonist action, ${ }^{7}$ orally to patients with cirrhosis. Nalmefene is a more potent antagonist than naloxone at all three main types of opioid receptors. ${ }^{7}$ When $300 \mathrm{mg}$ nalmefene was given orally to healthy people it produced only occasional, minor side effects. ${ }^{8}$

Department of Medicine, St James's University

Hospital, Leeds LS9 7TF

J R Thornton, MRCP, lecturer

M S Losowsky, FRCP, professor

Correspondence to:

Dr Thornton. nine had mitochondrial antibodies. One patient had cryptogenic cirrhosis, and one had alcoholic cirrhosis. This last patient had abstained from alcohol for 17 months. The table gives further baseline data on the patients.

In an attempt to perform a placebo controlled, randomised, double blind crossover trial we gave nalmefene or placebo to five of the patients on an outpatient basis. Three of them took the placebo for two weeks without any change in their symptoms or results of standard liver function tests. However, the two patients given nalmefene, in the lowest available dose of $5 \mathrm{mg}$, experienced a florid reaction after the first dose, which took three days to subside. They were unwilling to take further doses as outpatients, and consequently the trial proceeded on an inpatient, unblinded basis.

To try to minimise the reaction produced by nalmefene the 11 patients were given clonidine, a drug that ameliorates the symptoms of withdrawal of opiates in heroin addicts. ${ }^{9-11}$ The dose of nalmefene was gradually increased over seven to 10 days from $5 \mathrm{mg}$ twice daily to $20-40 \mathrm{mg}$ thrice daily. Clonidine $100 \mu \mathrm{g}$ thrice daily was given on the first three days of treatment with nalmefene and was reduced to $75 \mu \mathrm{g}$ thrice daily on day $4,50 \mu \mathrm{g}$ thrice daily on day 5 , and $25 \mu \mathrm{g}$ thrice daily on day 6 and was stopped on day 7 . Pulse rate and arterial pressure were monitored every hour for the first 12 hours on day 1 and every four hours thereafter.

All nine patients with primary biliary cirrhosis had pruritus. Four of them found that their itching was only partially alleviated by cholestyramine, and the remaining five were unable to take this drug because it worsened their steatorrhoea. To assess whether nalmefene was beneficial in alleviating these patients' itching any antipruritic drugs were stopped three weeks before the study. Pruritus was measured daily for two weeks before the study and then for two weeks at one, three, and six months; patients scored their pruritus on a visual analogue scale consisting of a $10 \mathrm{~cm}$ line ranging from "no itching" to "very itchy." Fatigue was assessed similarly, with a $10 \mathrm{~cm}$ scale ranging from "no energy" to "plenty of energy."

Plasma bilirubin and albumin concentrations and alanine aminotransferase and alkaline phosphatase activities were measured twice immediately before nalmefene was started and again at one, three, and six months. The nine patients with primary biliary cirrhosis had had all these measurements taken a median of six months (range five to seven months) before the study.

Details of 11 patients with cirrhosis before treatment with nalmefene

\begin{tabular}{|c|c|c|c|c|c|c|c|c|c|c|c|}
\hline $\begin{array}{c}\text { Case } \\
\text { No }\end{array}$ & $\begin{array}{l}\text { Type of } \\
\text { cirrhosis }\end{array}$ & Sex & $\begin{array}{c}\text { Age } \\
\text { (years) }\end{array}$ & Ascites & $\begin{array}{c}\text { Plasma } \\
\text { bilirubin } \\
(\mu \mathrm{mol} / \mathrm{l})\end{array}$ & $\begin{array}{c}\text { Plasma } \\
\text { albumin } \\
(\mathrm{g} / \mathrm{l})\end{array}$ & $\begin{array}{l}\text { Plasma } \\
\text { creatinine } \\
(\mu \mathrm{mol} / \mathrm{l})\end{array}$ & $\begin{array}{c}\text { Plasma } \\
\text { methionine } \\
\text { enkephalin } \\
(\mathrm{pmol} / \mathrm{l})\end{array}$ & $\begin{array}{c}\text { Plasma } \\
\text { leucine } \\
\text { enkephalin } \\
(\mathrm{pmol} / \mathrm{l})\end{array}$ & Other medical problems & Continued treatment \\
\hline 1 & Primary biliary & $\mathrm{F}$ & 67 & No & 173 & 41 & 91 & 295 & 660 & & \\
\hline 2 & Primary biliary & $\mathrm{F}$ & 41 & No & 139 & 34 & 77 & 240 & 575 & & \\
\hline 3 & Primary biliary & $\mathrm{F}$ & 47 & No & 108 & 44 & 83 & 335 & 615 & & \\
\hline 4 & Primary biliary & $\mathrm{F}$ & 59 & No & 80 & 28 & 67 & 215 & 430 & & \\
\hline 5 & Primary biliary & $\mathrm{F}$ & 48 & No & 78 & 37 & 90 & 190 & 295 & Cholecystectomy & \\
\hline 6 & Primary biliary & $\mathrm{F}$ & 70 & In past & 74 & 42 & 104 & 165 & 490 & & Spironolactone \\
\hline 7 & Primary biliary & $\mathrm{F}$ & 61 & No & 59 & 37 & 64 & 130 & 385 & & \\
\hline 8 & Primary biliary & $\mathrm{F}$ & 53 & No & 23 & 43 & 71 & 120 & 235 & & \\
\hline 9 & Primary biliary & $\mathrm{M}$ & 69 & No & 11 & 37 & 102 & 125 & 330 & Previous myocardial infarct & Frusemide, glyceryl trinitrate \\
\hline 10 & Alcoholic & $\mathrm{M}$ & 59 & Yes & 26 & 40 & 143 & 445 & 965 & Diabetes & Spironolactone, glibenclamide \\
\hline 11 & Cryptogenic & M & 34 & No & 22 & 33 & 104 & 270 & 315 & Splenorenal shunt, hepatic encephalopathy & \\
\hline
\end{tabular}


Data are expressed as medians with ranges. The significance of differences was determined by Wilcoxon's signed rank sum test.

\section{Results}

All the patients experienced a considerable reaction, which began within an hour of the first doses of the two drugs. The cerebral effects were invariably unpleasant and sometimes included visual or auditory hallucinations. Two patients' written accounts of these disturbances were: "Heavy, trembling limbs. Dream-like state. No energy. No concentration. Heavy eyelids. Wanted to sleep but couldn't. Didn't want to be bothered by anyone. Couldn't think. No appetite"; and, "Cold sweat. Dizzy. Very dry mouth. My mind felt white inside. Slept really badly, just cat napped. Too pepped up."

All of these patients experienced anorexia, nausea, colicky abdominal pain, and constipation. Over the first 12 hours of day 1 , compared with the same period of the preceding day, the median pulse rate fell from 74 (range $68-82$ ) beats/min to 61 (58-65) beats/min $(\mathrm{p}<0.01)$, systolic arterial pressure rose from 118 (113-164) $\mathrm{mm} \mathrm{Hg}$ to 132 (126-180) $\mathrm{mm} \mathrm{Hg}$ $(\mathrm{p}<0.01)$, and diastolic arterial pressure rose from 78 (70-91) $\mathrm{mm} \mathrm{Hg}$ to $83(79-97) \mathrm{mm} \mathrm{Hg}(\mathrm{p}<0.05)$. During the first day that they were taking nalmefene the patients were pale and had cool skin.

Despite this reaction all of the patients continued taking the drugs, except for the patient with cryptogenic cirrhosis, who refused further drugs after three days. Most of the patients' withdrawal symptoms settled within two or three days, though four patients had intermittent abdominal pain for up to two months. Nalmefene was stopped in the patient with alcoholic cirrhosis after six days because it did not improve his

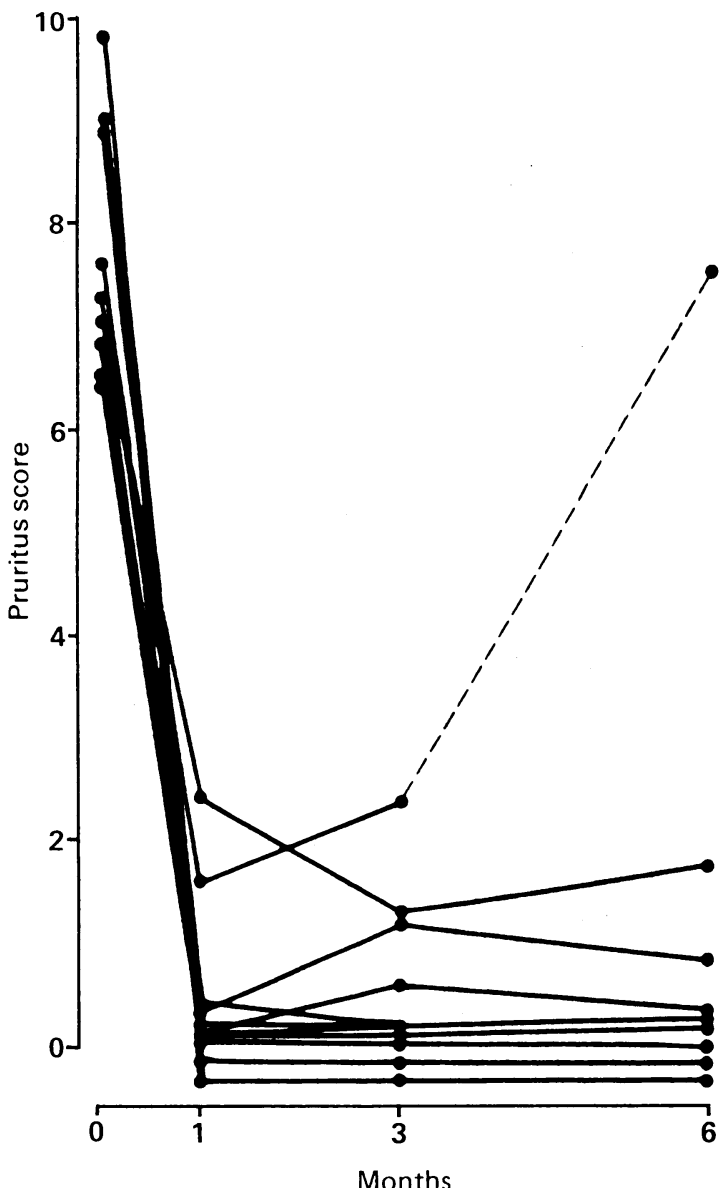

FIG 1-Effect of nalmefene on pruritus scores in nine patients with primary biliary cirrhosis. ----=Drug stopped

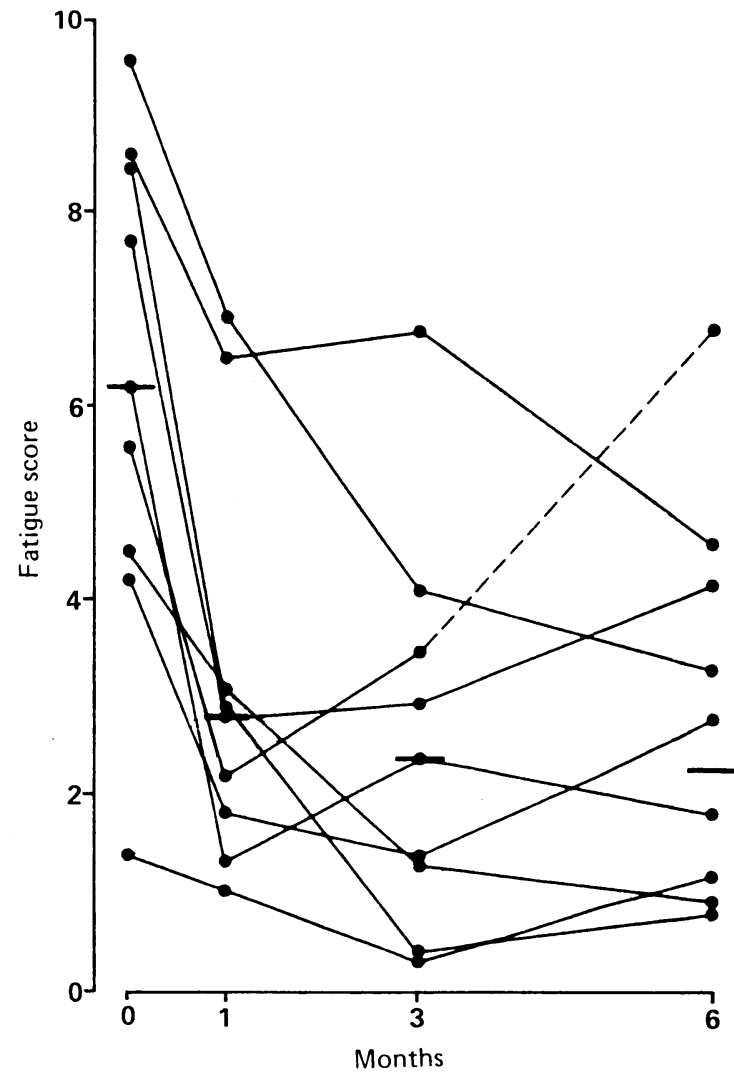

FIG 2-Effect of nalmefene on fatigue scores. ----=Drug stopped. Horizontal bars are median values

worsening ascites. It was also withdrawn in case 3 after four months because, although the patient felt better when taking the drug, her bilirubin concentration, after an initial fall, began to rise, and we could not exclude the possibility that this effect was drug induced. The remaining eight patients continued taking nalmefene for over six months.

All nine patients with itching noticed an immediate, considerable improvement in this symptom. At one month their pruritus score had fallen from $7 \cdot 6(6 \cdot 4-9 \cdot 8)$ to $0 \cdot 2(0-2 \cdot 4 ; \mathrm{p}<0.001)$, and this improvement was sustained at three months $(0.2(0-2.6) ; \mathrm{p}<0.001)$ and six months $(0.3(0-1.8) ; \mathrm{p}<0.001)$ (fig 1). The patients' sense of fatigue also improved: before taking nalmefene their score was $6 \cdot 2(1 \cdot 3-9 \cdot 6)$, at one month it was $2.6(1.0-6.9 ; \mathrm{p}<0.01)$, at three months it was $2.4(0.6-6.8 ; \mathrm{p}<0.01)$, and at six months it was 2.3 $(0 \cdot 8-4 \cdot 6 ; \mathrm{p}<0.01)$ (fig 2$)$.

Plasma bilirubin concentration, which had risen from $60(8-122) \mu \mathrm{mol} / 1$ to $72(11-173) \mu \mathrm{mol} / \mathrm{l}(\mathrm{p}<0.05)$ in the six months before the patients were given nalmefene, fell to $54(11-162) \mu \mathrm{mol} / \mathrm{l}$ at one month $(\mathrm{p}<0.01), 58(11-143) \mu \mathrm{mol} / \mathrm{l}$ at three months $(\mathrm{p}<0.05)$, and $48(14-138) \mu \mathrm{mol} / \mathrm{l}$ at six months $(\mathrm{p}<0.02)$ (fig 3). Plasma albumin concentration and alkaline phosphatase and alanine aminotransferase activities did not alter significantly at any time during the study.

The three patients with the lowest baseline bilirubin concentration (cases 7-9) took nalmefene $20 \mathrm{mg}$ thrice daily throughout the study. The six other patients were discharged from hospital taking nalmefene $40 \mathrm{mg}$ thrice daily. Fatigue responded least well in case 2 , and so the dose of nalmefene was increased at three months to $60 \mathrm{mg}$ thrice daily with some apparent benefit (fig 2 ).

\section{Discussion}

All the patients experienced a considerable reaction when first given nalmefene and clonidine. Clonidine, even in larger doses than those that we gave, has not been reported to produce adverse reactions in patients 
with liver disease. ${ }^{12}{ }^{13}$ Moreover, the same reaction occurred in the two patients initially given nalmefene alone. These effects were thus clearly a consequence of nalmefene's antagonist action at opioid receptors and not side effects because they were invariable, were temporary, have not been observed when nalmefene has been given to patients with various other diseases, and occurred at a dose one sixtieth of that which produces only occasional, minor cerebral effects, such as feelings of light headedness, in healthy subjects. ${ }^{8}$ Similarly, the opioid antagonist naloxone has minimal or no subjective effects in normal subjects, even at high doses, ${ }^{14}$ whereas much smaller quantities are sufficient to precipitate intense withdrawal symptoms in opiate addicts. ${ }^{15}$

Increasing evidence suggests that a sustained rise in plasma concentrations of pentapeptide enkephalins allows them to penetrate the blood-brain barrier, ${ }^{17-20}$ though such a rise is not always shown after a single bolus injection. ${ }^{16}$ Like opiate drugs, opioid peptides produce cerebral dependence when given continually, ${ }^{21}$ even when given by a peripheral route..$^{22}$ Because our patients had raised plasma concentrations of at least two opioid peptides it is not surprising that they experienced an apparent withdrawal reaction when given an opioid antagonist.

The patients' immediate response to nalmefene has many similarities to the withdrawal reaction seen in opiate addiction..$^{911}$ In both reactions unpleasant cerebral disturbances, anorexia, nausea, abdominal pain, sweating, pallor, and a rise in arterial pressure occur. Arterial pressure rose in the patients with cirrhosis despite the hypotensive action of clonidine given concomitantly. Whereas heart rate rises in opiate addicts during withdrawal, our patients experienced a relative bradycardia. This was probably at least partly caused by the clonidine. Constipation was a surprising but temporary effect in our patients. With the exception of intermittent, colicky abdominal pain all the adverse effects resolved within the first week and were often minimal after two or three days, which

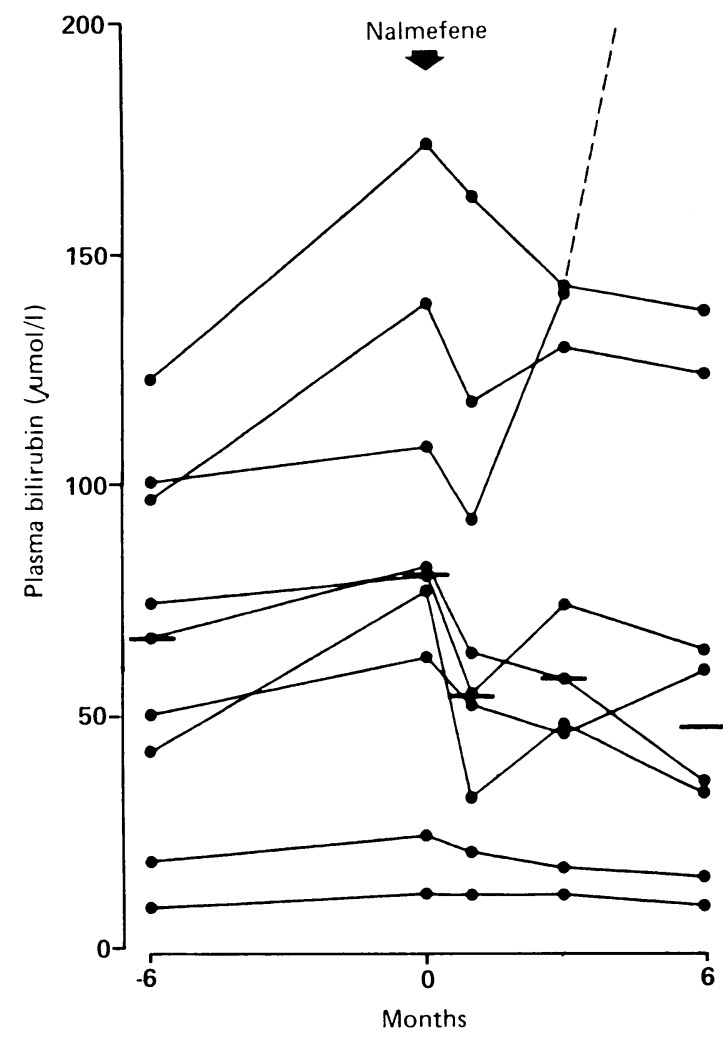

FIG 3-Plasma bilirubin concentrations in nine patients with primary biliary cirrhosis before and after starting nalmefene. ----=Drug stopped. Horizontal bars are median values allowed clonidine to be tailed off and stopped after six days.

The cause of pruritus in cholestasis is uncertain. Methionine enkephalin may be excreted in bile. ${ }^{2}$ We hypothesise that biliary excretion may be quantitatively more important for those opioid peptides comprising 10 or more amino acids, which, unlike methionine enkephalin, ${ }^{2}$ are fairly resistant to enzymatic breakdown, ${ }^{23}$ and that plasma concentrations of these larger peptides may therefore be increased in patients with cholestasis. These larger peptides are potent releasers of inflammatory mediators from mast cells, including histamine..$^{25-28}$ The alleviation of the patients' pruritus by nalmefene was considerable, apparent after the first dose, and sustained. The patients scratched themselves repeatedly before nalmefene was given but almost stopped doing so after starting to take the drug, and their scratch marks disappeared. This effect of nalmefene therefore seems to be more than a placebo reaction. It is probably a consequence of the inhibition of opioid peptides, which cause pruritic substances to be liberated, because unpublished trials of nalmefene in itchy skin disorders have not shown any direct antipruritic action of the drug.

The alleviation of fatigue by nalmefene was less impressive. Conceivably the high plasma methionine and leucine enkephalin concentrations in patients with cirrhosis $^{3.5}$ may contribute to fatigue in liver disease by a direct action on the central nervous system ${ }^{17-20}$ and this fatigue may have been alleviated by blocking opioid receptors with nalmefene. An improvement in the patients' sleep after their pruritus had been relieved may also have played a part. A placebo response cannot, however, be excluded.

Plasma bilirubin concentration had been rising in most of the patients with primary biliary cirrhosis. It fell in all of them when they started taking nalmefene and six months later remained below the baseline value in eight of them. This finding suggests that there may be a metabolic contribution to the cholestasis of primary biliary cirrhosis that is caused by increased activity of opioid peptides. One patient, however, developed deepening jaundice three months after starting nalmefene. This was probably coincidental because it continued to worsen when the drug was stopped and she had had a bilirubin concentration of over $100 \mu \mathrm{mol} / \mathrm{l}$ before starting nalmefene, which often indicates rapidly progressive cholestasis. ${ }^{29}$

The patients' plasma albumin concentrations and alkaline phosphatase and alanine aminotransferase activities did not alter significantly with nalmefene. This suggests that the drug affects some of the metabolic abnormalities of liver disease without affecting the disease process itself.

The doses of nalmefene were empirical, and we did not measure the plasma concentrations of the drug. Nalmefene is eliminated predominantly in urine, partly after conjugation with glucuronic acid in the liver. ${ }^{30}$ There are no reports of hepatotoxicity caused by nalmefene.

From these results we recommend that nalmefene is started in hospital, that the initial dose is as low as possible, and, perhaps, that a higher dose of clonidine than we used is given for the first few days. Under these conditions it should be possible to determine whether opioid peptides contribute to other manifestations of liver disease $\mathrm{e}^{23}$ and to evaluate the possible value of nalmefene in liver disease.

\footnotetext{
Imura H, Kato Y, Nakai Y, el al. Endogenous opioids and related peptides: from molecular biology to clinical medicine. I Endocrinol 1985;107:147-57. Thornton JR, Losowsky MS. Methionine enkephalin is increased in plasma in acute liver disease and is present in bile and urine. $f$ Heputol (in press)

3 Thornton JR, Dean H, Losowsky MS. Is ascites caused by impaired hepatic inactivation of blood-borne endogenous opioid peptides? Gut 1988;29. 1167-72. 
4 Thornton JR, Losowsky MS. Plasma methionine enkephalin concentration and prognosis in primary biliary cirrhosis. Br Med f 1988;297:1241-2.

Thorn JR Lusowsky MS. Plasma leucine enkephalin is increased in liver diseave. Gut 1988:29: A1429.

6 Thornton JR, Losowsky MS. A role for the kidneys and liver in plasm beta-endorphin elimination? Clin Sci 1988;74(suppl 18):51P.

7 Michel ME, Bolger G, Weissman B-A. Binding of a new opiate antagonist, nalmefene, to rat brain membranes. Methods Find Exp Clin Pharmaco $1985 ; 7: 175-7$

8 Gal TJ, DiFazio CA, Dixon R. Prolonged blockade of opioid effect with ora nalmefene. Clin Pharmacol Ther 1986;40:537-42.

9 Gold MS, Redmond DE, Kleber HD. Clonidine blocks acute opiatewithdrawal svmptoms. Lancet 1978;ii:599-602.

10 Washton AM, Resnick RB. Clonidine for opiate detoxification. Out-patien clinical trials. A $m$ f Psychiatry 1980;137:1121-2.

11 Charnev DS, Heninger GR, Kleber HD. The combined use of clonidine and naltrexone as a rapid, safe and effective treatment of abrupt withdrawal from methadone Am $\mathcal{A}$ Psychiutry 1986:143:831-7.

12 Willet IR, Esler Mt Jennings G, Dudler. FJ Sympatheric tone modulates portal venous pressure in alcoholic cirrhosis. Lancet 1986;ii:939-43.

13 Moreau R, Lec SS, Hadengue A, Braillon A, Lebrec D. Hemodynamic effects of a clonidine-induced decrease in sympathetic tone in patients with cirrhosis. Hepatology 1987;7:149-54.

14 Grossman a Stubbs WA Gaillard RC, Delitala G, Rees LH, Besser GM Studies of the opiate control of prolactin, GH and TSH. Clin Endocrinol Oxf) $1981 ; 14: 381-6$.

15 Resnick RB, Kestenbaum RS, Washton A, Poole D. Naloxone-precipitated withdrawal: a method for rapid induction onto naltrexone. Clin Pharmaco Ther 1977:21:409-13.

16 Cornford EM, Braun LD, Crane PD, Oldendorf WH. Blood-brain barrier restriction of peptides and the low uptake of enkephalins. Endocrinology 1978; 103:1297-303

17 Kastin AJ, Nissen C. Schally AV, Coy DH. Blood-brain barrier, half-time disappearance and brain distribution for labelled enkephalin and a potent analog. Brain Res Bull 1976:1:583-9.
18 Rapoport SI, Klee WA, Pettigrew KD, Ohno K. Entry of opioid peptides into the central nervous system. Science 1980;207:84-6.

19 Banks WA, Kastin AJ, Fischman AJ, Coy DH, Strauss SL. Carrier-mediate transport of enkephalins and N-tyr-MIF-1 across blood-brain barrier. Am J Physiol 1986;251:E477-82.

20 Zlokovic BV, Lipovac MN, Begley DJ, Davson H, Rakic L. Transport of leucine-enkephalin across the blood-brain barrier in the perfused guinea pig brain. F Neurochem 1987:49:310-5.

21 Wei E, Loh H. Physical dependence on opiate-like peptides. Science 1976;193:1262-3.

22 Gmerek DE, Woods JH. Kappa receptor mediated opioid dependence in rhesus monkeys. Life Sci 1986;39:987-92.

23 Corbett AD, Paterson SJ, McNight AT, Magnan J, Kosterlitz HW. Dynorphin 1-8 and dynorphin 1-9 are ligands for the $x$-subtype of opiate receptor. Nature 1982;299:79-81.

24 Hersh LB. Reaction of opioid peptides with neutral endopeptidase ("enkephalinase"). 7 Neurochem 1984;43:487-93.

25 Yamasaki Y, Shimamura O, Kizu A, Nakagawa M, Ijichi H. IgE-mediated ${ }^{14} \mathrm{C}$-serotonin release from rat mast celis modulated by morphine and endorpins. Life $S_{c i} 1982 \cdot 31 \cdot 4718$.

26 Casale TB, Bowman S, Kaliner M. Induction of human cutaneous mast cell degranulation by opiates and endogenous opioid peptides: evidence for opiate and non-opiate receptor participation. 7 Allergy Clin Immunol 1984:73:775-81.

27 Shanahan F, Lee TDG, Bienenstock J, Befus AD. The influence of endorphins on peritoneal and mucosal mast cell secretion. $\mathcal{F}$ Allergy Clin Immunol 1984;74:499-504.

28 Sugiyama $\mathrm{K}$, Furata $\mathrm{H}$. Histamine release induced by dynorphin-(1-13) from rat mast cells. Fapanese fournal of Pharmacologv 1984;35:247-52.

29 Shapiro JM, Smith H, Schaffner F. Serum bilirubin: a prognostic factor in primary biliary cirrhosis. Gut 1979;20:137-40.

30 Dixon R, Howes J, Gentile J, et al. Nalmefene: intravenous safety and kinetics of a new opioid antagonist. Clin Pharmacol Ther 1986;39:49-53.

(Accepted 4 November 1988

\section{Computerised updating of clinical summaries: new opportunities for clinical practice and research?}

Department of Medicine, King's College School of Medicine and Dentistry, Denmark Hill, London SE5 8RX

D E Huw Llewelyn, MD, senior lecturer

David L Ewins, MRCP, registrar

Jackie Horn, secretarial research assistant Alan M McGregor, $\mathrm{MD}$, professor of medicine

Paxton Green Health Centre, London SE21 8AU Tyrrell G R Evans, MRCGP, general practitioner

Correspondence to: Dr Llewelyn.

\section{E Huw Llewelyn, David L Ewins, Jackie Horn, Tyrrell G R Evans, Alan M McGregor}

\begin{abstract}
A new type of clinical summary, produced by copying standard descriptions of diseases on to a computer screen and editing them to match a patient's findings and diagnoses, was updated and reprinted as the patient's condition changed in the ward or as an outpatient. When this method was used to produce typed medical discharge summaries over a three month period, 73 out of $91(80 \%)$ were sent out within a week after discharge compared with five out of $56(9 \%)$ conventionally typed summaries received in a single general practice.

Even completely new computerised summaries are quicker for the secretary to produce than conventional summaries, and the computerised summaries are designed to be scanned rapidly for relevant information. They can also be used to collect data automatically for research, clinical audit, and resource management.
\end{abstract}

\section{Introduction}

Few computer systems have been designed to help hospital doctors and secretaries avoid tedious repetition and to save time when clinic letters and discharge summaries are being dictated and typed. Word processing software can reduce the amount of dictating and typing required by allowing the copying of standard paragraphs into a document, but this approach has been applied to medicine only in a limited way, for copying simple phrases into standard letters. This technique is difficult to apply when there are many diagnoses because the conventional letter or summary does not give the findings and the management of each diagnosis together in single blocks of text that can be transferred conveniently. Instead, the details of a single diagnosis are dispersed in different sections describing the history, examination, and investigations. This problem can be overcome by using a special format for the clinical summary and for the standard text.

\section{Methods}

The software system used in the study was an application of Lotus Symphony run on an IBM PC AT microcomputer. The format of the summary was based on three columns: findings, diagnoses, and management. Each column was divided into blocks of text, which were aligned horizontally and represented a single diagnosis (table I). The summary was drafted by copying the standard blocks of text from a library of entries held on a computer disk into the summary, which was then printed out. The entries on this printout were then edited by the doctor until they represented the patient's details (table II) and the changes were entered into a computer file by the secretary.

The doctor was able to check for clinical omissions and other errors as he edited the summary. This could be done while the patient was still in the ward, when any missing information was easily available. The consultant, other doctors, nurses, paramedical staff, and students caring for the patient could thus refer to the summary and comment or ask about its contents. When the patient was seen in a follow up clinic or readmitted the summary could be updated and reprinted.

\section{ASSESSMENT OF THE SYSTEM}

The new summaries were produced for all routine and emergency patients admitted to a medical department under the care of two consultant physicians over three months. The time from discharge of the patient to completion of the final summary was recorded in three different groups of patients: those admitted under the care of the two consultants who were using the new system; those admitted during the same period 